\title{
Altered expression of PPAR- $\gamma$ and TRPC in neonatal rats with persistent pulmonary hypertension
}

\author{
YANNA DU, JIANHUA FU, LI YAO, LIN QIAO, NA LIU, YUJIAO XING and XINDONG XUE \\ Department of Pediatrics, Shengjing Hospital of China Medical University, Shenyang, Liaoning 110004, P.R. China
}

Received May 19, 2016; Accepted April 4, 2017

DOI: $10.3892 / \mathrm{mmr} .2017 .6744$

\begin{abstract}
Persistent pulmonary hypertension of the newborn (PPHN) is a life-threatening disease that is commonly observed in the neonatal intensive care unit. PPHN is pathologically characterized by pulmonary vascular remodeling and, in particular, pulmonary artery smooth muscle cell (PASMC) proliferation. Decreased expression levels of peroxisome proliferator-activated receptor $\gamma$ (PPAR- $\gamma$ ), which is a member of the nuclear receptor hormone superfamily, in combination with elevated expressions of transient receptor potential cation channel, subfamily C, member 1 (TRPC1) and TRPC6 contributes to the PASMC proliferation and excessive pulmonary vascular remodeling in adult pulmonary hypertension $(\mathrm{PH})$. Whether PPAR- $\gamma$, TRPC1 and TRPC6 affect the development of vascular remodeling in PPHN model rats remains unknown. The aim of the present study was to investigate the roles of PPAR- $\gamma$, TRPC1 and TRP6 on the pathogenesis of PPHN in rats. The rat model of PPHN was established by exposure to hypoxic conditions and indomethacin treatment. Lung tissues, hearts and blood from PPHN model and Control rats were collected and examined. Parameters, including the percentage of medial wall thickness (WT \%), the percentage of medial wall area (WA \%), right ventricular hypertrophy (RVH) and the plasma concentration of B-type natriuretic peptide (BNP) were used to estimate the development of PPHN. The expression levels of PPAR- $\gamma$, TRPC1 and TRPC6 in lung tissues were detected by immunohistochemistry, western blotting and reverse transcription-quantitative polymerase chain reaction. Significant increases were observed in the WT \%, WA \%,
\end{abstract}

Correspondence to: Professor Xindong Xue, Department of Pediatrics, Shengjing Hospital of China Medical University, 36 Sanhao Street, Shenyang, Liaoning 110004, P.R. China

E-mail: xuexd@sj-hospital.org

Abbreviations: BNP, B-type natriuretic peptide; PASMC, pulmonary artery smooth muscle cell; $\mathrm{PH}$, pulmonary hypertension; PPAR- $\gamma$, peroxisome proliferator-activated receptor $\gamma$; PPHN, persistent pulmonary hypertension of the newborn; TRPC, transient receptor potential cation channel

Key words: PPAR- $\gamma$, TRPC1, TRPC6, pulmonary vascular remodeling, persistent pulmonary hypertension of the newborn
$\mathrm{RVH}$ and plasma BNP in the PPHN group compare with the Control group $(\mathrm{P}<0.01)$. In addition, the mRNA and protein expression levels of PPAR- $\gamma$ were markedly downregulated $(\mathrm{P}<0.05$ vs. Control). In the PPHN group, the protein expression levels of TRPC1 and TRPC6 were higher compared to the control group; however, there was no difference in the mRNA expression levels $(\mathrm{P}>0.05)$. In conclusion, the present study successfully established a PPHN rat model, and the altered expressions of PPAR- $\gamma$, TRPC1 and TRPC6 in the pulmonary artery located in the lungs of newborn rats with PPHN suggested that these proteins may be important mediators of PPHN.

\section{Introduction}

Persistent pulmonary hypertension of the newborn (PPHN) is a common, yet deleterious condition that is observed in the neonatal intensive care unit and has high mortality and variable morbidity rates (1). The etiology of PPHN is complex; however, several studies $(2,3)$ have reported that the main causes of this condition include hypoxia and constriction of the fetal ductus arteriosus in utero, which may occur following exposure to non-steroidal anti-inflammatory drugs (NSAIDs) during the third trimester (4). PPHN is pathologically characterized by pulmonary vascular remodeling (5), which comprises smooth muscle cell proliferation and adventitial hypertrophy (6); pulmonary artery smooth muscle cell (PASMC) proliferation is a major contributor to pulmonary vascular remodeling (7).

In PASMCs, a rise in cytosolic $\mathrm{Ca}^{2+}$ concentration is considered to be a key stimulus for proliferation $(8,9)$. A previous study has demonstrated that of the three main extracellular calcium influx pathways, voltage-operated calcium entry, receptor-operated calcium entry and store-operated calcium entry (SOCE), hypoxia was able to enhance SOCE through store-operated calcium channels (SOCCs) (10). Furthermore, transient receptor potential cation channels (TRPCs) are the main components of SOCCs (11). In adult animal models of hypoxia-induced pulmonary hypertension (PH), high expression levels of canonical TRPC, subfamily $\mathrm{C}$, member 1 (TRPC1) and TRPC6 were revealed to contribute to excessive pulmonary vascular remodeling (11). Whether the elevated expression of TRPC1 and TRPC6 results in increased PASMC proliferation and contributes to pulmonary vascular remodeling in PPHN model rats is unknown. 
Peroxisome proliferator-activated receptor $\gamma(\operatorname{PPAR}-\gamma)$ is a member of the nuclear receptor hormone superfamily $(12,13)$ and is considered to serve a vital role in cell differentiation, development, metabolism, inflammation and tumorigenesis (13). It is widely expressed in pulmonary vascular endothelial and smooth muscle cells in normal human lungs and regulates vascular smooth muscle cell proliferation (14). A number of studies have indicated that a decrease of PPAR- $\gamma$ expression may contribute to the development of PH $(10,15)$. In addition, mice with selective deletion of PPAR $-\gamma$ in PASMCs were reported to spontaneously develop $\mathrm{PH}$ and exhibited increased muscularization of the distal pulmonary arteries (16). In addition, PPAR- $\gamma$ deletion was revealed to induce human PASMC (HPASMC) proliferation in vitro and PPAR- $\gamma$ overexpression reduced HPASMC proliferation in vitro (17). In adult rat models of PH, treatment with PPAR- $\gamma$ agonists were demonstrated to protect against vascular remodeling and $\mathrm{PH}$ (18).

Decreased PPAR- $\gamma$ expression may contribute to PASMC proliferation and vascular remodeling in adult models of $\mathrm{PH}$. Whether changes to the level of expression of PPAR- $\gamma$ contributes to PPHN in newborn rats remains unclear. Thus, the aim of the present study was to establish a PPHN rat model and to investigate whether the PPAR- $\gamma /$ TRPC pathway is altered in PPHN.

\section{Materials and methods}

Animal models. All animal procedures and protocols were approved by the Committee on the Ethics of Animal Experiments at China Medical University (Shenyang, China). All surgeries were performed under chloral hydrate anesthesia, and all efforts were made to minimize animal suffering.

A total of 10 specific pathogen free healthy female Sprague-Dawley (SD) rats (weight, 250-300 g; age, 7-8 weeks old) were provided by the Experimental Animal Center of Shengjing Hospital of China Medical University (Shenyang, China). All rats had free access to food and water, and were housed at $25-27^{\circ} \mathrm{C}$ and $50-70 \%$ humidity with a 12 -h light/dark cycle. The female rats were mated overnight; this was considered day 0 of gestation. A combination of hypoxic conditions and treatment with the NSAID indomethacin was used to establish a rat model of PPHN, as previously described (19) Briefly, on gestation day 19, pregnant rats were randomly assigned to either the PPHN model or the Control group (n=5/group). Firstly, indomethacin $(0.5 \mathrm{mg})$ was dissolved in $10 \mathrm{ml}$ of $38 \%$ alcohol (sterile distilled water and ethanol; cat. no. I7378; Sigma-Aldrich, Merck KGaA, Darmstadt, Germany). During days 19 to 21 of gestation, pregnant rats in the PPHN group were subjected to hypoxic conditions (oxygen concentration, $10 \pm 0.5 \%$ ) and treated with indomethacin $(0.5 \mathrm{mg} / \mathrm{kg})$ by intraperitoneal injection twice a day. However, during days 19 to 21 of gestation the pregnant rats in the Control group were housed under standard normoxic conditions (oxygen concentration, 21\%) and treated with isotonic saline by intraperitoneal injection twice a day. On day 22 , the fetuses were born by cesarean section from both groups. In both groups, 50 fetuses were randomly selected, sacrificed and samples were collected as described below.

Preparation of the lungs and hearts. Lungs and hearts were isolated from the newborn rats and prepared for further examination. The inferior lobe of the right lung was fixed in $4 \%$ paraformaldehyde for $24 \mathrm{~h}$ at $4^{\circ} \mathrm{C}$, embedded in paraffin and sectioned (4-5 $\mu \mathrm{m})$ prior to staining with hematoxylin and eosin, or immunohistochemical analysis. The remaining lung tissue was stored at $-70-80^{\circ} \mathrm{C}$ for western blot analysis and mRNA detection. Following collection of fetal hearts, the left atrium, right atrium and free large vessels were removed. In addition, the right ventricle (RV) free wall was removed from the left ventricle (LV) and septum (SV) under a stereomicroscope. Then the weight of the RV, LV and septum were measured. The RV hypertrophy index (RVHI) was calculated to evaluate the PPHN model, which was assessed by the ratio of the weight of the RV to that of the LV plus SV: $\mathrm{RVHI}=\mathrm{RV} /(\mathrm{LV}+\mathrm{SV})$.

Hematoxylin and eosin (H\&E) staining, immunohistochemistry and measurement of vascular remodeling. The paraffin-embedded sections were stained with H\&E and immunohistochemical staining. Briefly, sections of lung (4-5 $\mu \mathrm{m}$ thick) were deparaffinized in graded alcohol solutions and xylene, and stained with H\&E using a H\&E Staining kit (cat. no. G1120; Beijing Solarbio Science \& Technology Co., Ltd., Beijing, China). Immunohistochemical analysis was performed to identify the $\alpha$ smooth muscle actin ( $\alpha$-SMA) content present in the paraffin-embedded lung tissue samples. The $\alpha$-SMA antibody can be used for marking vascular smooth muscle, thus, in the present study, medial thickness and medial area occupied by smooth muscle was determined by positive $\alpha$-SMA staining; circular areas of positive $\alpha$-SMA staining can also indirectly represent the smooth muscle of the pulmonary artery or distal pulmonary arterioles $(20,21)$.

Briefly, sections of lung (4-5 $\mu$ m thick) were deparaffinized in graded alcohol solutions and xylene. Following the manufacturer's instructions (immunohistochemistry kit; cat. no. SP-9002; Beijing Zhongshan Golden Bridge Biotechnology Co., Ltd.; OriGene Technologies, Inc., Beijing, China), all sections were then blocked with $3 \% \mathrm{H}_{2} \mathrm{O}_{2}\left(37^{\circ} \mathrm{C}\right.$, $20 \mathrm{~min}$ ) and goat serum (40 $\mathrm{min}$ at room temperature). Subsequently, sections were incubated overnight at $4^{\circ} \mathrm{C}$ with the $\alpha$-SMA primary antibody (1:100; mouse anti-rat $\alpha$-SMA; cat. no. ab7817; Abcam, Cambridge, UK). The negative control tissues were incubated with phosphate-buffered saline instead of the primary antibody. The next day, sections were incubated with the biotin-labeled goat anti-mouse IgG secondary antibody $\left(20 \mathrm{~min}\right.$ at $\left.37^{\circ} \mathrm{C}\right)$ and then incubated with a horseradish peroxidase marker $\left(20 \mathrm{~min}\right.$ at $\left.37^{\circ} \mathrm{C}\right)$. The paraffin sections were developed with 3 '-diaminobenzidine and counterstained with $10 \%$ hematoxylin for $3 \mathrm{~min}$ at room temperature; they were then dehydrated in a gradient of alcohol, treated with xylene and mounted using neutral balsam. A light microscope was used for image acquisition, and the deposition of brown particles indicated a positive result. A total of 3 paraffin-embedded sections were randomly selected from 10 random rats/group and 5 pulmonary arterioles with a diameter of 50 to $100 \mu \mathrm{m}$ from each rat were then selected. The pulmonary artery medial wall thickness/external diameter ratio (WT \%) and pulmonary artery medial wall cross-sectional area/total vessel area (WA \%) were determined from the images by analysis using Image-Pro Plus v6.0 software (Media Cybernetics; Rockville, MD, USA) to assess medial wall hypertrophy. 
Plasma B-type natriuretic peptide (BNP) concentration analysis by ELISA. Blood $(\sim 2 \mathrm{ml})$ was collected from 10newborn rats per group following decapitation, and placed into an EDTA anticoagulation tube. Blood samples were centrifuged at $1,600 \times \mathrm{g}$ for $20 \mathrm{~min}$ at $4^{\circ} \mathrm{C}$, and plasma was removed and stored at $-80^{\circ} \mathrm{C}$ for further study. Plasma BNP concentrations were measured using the Rat BNP 32 ELISA kit (cat. no. ab108815; Abcam), according to the manufacturer's protocol. The plates were read at a wavelength of 450 nm (Tecan Sunrise Microplate reader; Tecan Group Ltd., Männedorf, Switzerland) and the level of BNP was determined for each sample from a standard curve. In the present study, 10 samples from each group were used and experiments on each sample were repeated 3 times.

Western blot analysis. Samples $(80 \mathrm{mg})$ were obtained from 8 different rats/group. Briefly, to each lung sample $600 \mu \mathrm{l}$ radioimmunoprecipitation lysis buffer (Beyotime Institute of Biotechnology, Shanghai, China) and $6 \mu$ l PMSF (Beyotime Institute of Biotechnology) were added. Samples were then agitated using ultrasonication, left for $10 \mathrm{~min}$ then centrifuged at $14,000 \times \mathrm{g}$ and $4^{\circ} \mathrm{C}$ for $30 \mathrm{~min}$. The supernatants were then collected. The total protein extracted from lung tissue was quantified using the bicinchoninic acid assay. A total of $50 \mu \mathrm{g}$ of each protein extract was separated by $8 \%$ SDS-PAGE and transferred onto polyvinylidene difluoride membranes (EMD Millipore, Billerica, MA, USA). The membranes were incubated for $2-3 \mathrm{~h}$ in $5 \%$ bovine serum albumin to block nonspecific binding. Following blocking, the membranes were incubated with primary antibodies against PPAR- $\gamma(1: 400$; rabbit polyclonal; cat. no. ab19481; Abcam), TRPC1 (1:200; rabbit polyclonal; cat. no. T8276; Sigma-Aldrich; Merck KGaA), TRPC6 (1:200, rabbit polyclonal; cat. no. T6442; Sigma-Aldrich; Merck KGaA) and GAPDH (1:5,000; mouse monoclonal; cat. no. ab9484; Abcam), diluted in Tris-buffered saline $+1 \%$ Tween-20 (TBST) overnight at $4{ }^{\circ} \mathrm{C}$. Membranes were washed in TBST and incubated for $2 \mathrm{~h}$ at room temperature with horseradish peroxidase-conjugated goat anti-rabbit or goat anti-mouse antibodies (1:2,000; cat. nos. ZB-2301 or ZB-2305, respectively; Beijing Zhongshan Golden Bridge Biotechnology Co., Ltd.; OriGene Technologies, Inc.) and visualized using enhanced chemiluminescence reagents (Santa Cruz Biotechnology, Inc., Dallas, TX, USA). Densitometric analysis of the protein bands was performed using Image-Pro Plus software v6.0 (Media Cybernetics, Inc.) and then normalized to GAPDH.

Total RNA extraction and reverse transcription-quantitative polymerase chain reaction ( $R T-q P C R$ ). Eight samples (70 mg) from each group were obtained and total RNA was extracted using TRIzol reagent (Takara Biotechnology Co., Ltd., Dalian, China), according to the manufacturer's protocol. RNA purity and concentration were determined according to the OD 260/280 nm ratio. mRNA was reverse transcribed into cDNA using the PrimeScript RT Reagent kit (Takara Biotechnology Co., Ltd.). PCR was performed with a $20 \mu$ l final volume reaction mixture SYBR-Green PCR reagent kit (Takara Biotechnology Co., Ltd.) according to the manufacturer's instructions, on the Applied Biosystems 7500 Real-Time PCR system (Applied Biosystems 7500; Thermo Fisher Scientific,
Table I. Primer sequences used for reverse transcriptionquantitative polymerase chain reaction.

\begin{tabular}{lc}
\hline Gene & \multicolumn{1}{c}{ Primer sequence $\left(5^{\prime} \rightarrow 3^{\prime}\right)$} \\
\hline PPAR- $\gamma$ & F: ACCACAGTTGATTTCTCC AG \\
& R: TGTTGTAGAGCTGGGTCTTT \\
TRPC1 & F: AGCCTCTTGACAAACGAGGA \\
& R: ACCTGACATCTGTCCGAACC \\
TRPC6 & F: TACTGGTGTGCTCCTTGCAG \\
& R: GAGCTTGGTGCCTTCAAATC \\
GAPDH & F: AGACAGCCGCATCTTCTTGT \\
& R: CTTGCCGTGGGTAGAGTCAT
\end{tabular}

F, forward; PPAR- $\gamma$, peroxisome proliferator-activated receptor $\gamma$; R, reverse; TRPC, transient receptor potential cation channel.

Inc., Waltham, MA, USA). The cDNA PCR conditions were as follows: 1 cycle of $95^{\circ} \mathrm{C}$ for $30 \mathrm{sec}$, then 40 cycles of $95^{\circ} \mathrm{C}$ for $5 \mathrm{sec}$ and $60^{\circ} \mathrm{C}$ for $34 \mathrm{sec}$. The gene expression levels were calculated with the $2^{-\Delta \Delta C q}$ method (22). GAPDH served as an internal control. Primer sequences are provided in Table I.

Statistical analysis. Data were presented as the mean \pm standard deviation. Statistical analysis was performed by Student's t-test, using the SPSS version 17.0 software (SPSS, Inc., Chicago, IL, USA). $\mathrm{P}<0.05$ was considered to indicate a statistically significant difference.

\section{Results}

Pulmonary vascular remodeling. H\&E staining revealed that when compared with the control group (Fig. 1A), the small pulmonary artery wall was thicker in the PPHN group (Fig. 1B).

The $\alpha$-SMA antibody can be used to mark vascular smooth muscle, thus, in the present study, circular areas of positive $\alpha$-SMA staining indirectly indicated the smooth muscle of the pulmonary artery or distal pulmonary arterioles. When compared with the control group (Fig. 2A), the pulmonary arterial medial wall was thicker in the PPHN group (Fig. 2C). In addition, when compared with the control group (Fig. 2B), the distal pulmonary arterioles were greatly increased in the PPHN group (Fig. 2D), which indicated that muscularization of distal pulmonary arterioles was increased in the PPHN group, when compared with the control group.

The small pulmonary arteries (50-100 $\mu \mathrm{m}$ in diameter) were compared, and the WT \% in the PPHN group was higher than that of the control group $(\mathrm{P}<0.01$; Fig. $3 \mathrm{~A})$. In addition, the WA \% of the PPHN group was also significantly greater than that of the control group $(\mathrm{P}<0.01$; Fig. $3 \mathrm{~B})$.

Right ventricle hypertrophy. Compared with the control group, the RVHI $[\mathrm{RV} /(\mathrm{LV}+\mathrm{SV})]$ was significantly increased in the PPHN group $(\mathrm{P}<0.01$; Fig. 3C).

Plasma BNP levels. Plasma BNP concentration was measured to indirectly reflect the pulmonary arterial pressure. In the PPHN group, the plasma BNP level was $872 \pm 35 \mathrm{pg} / \mathrm{ml}$, 

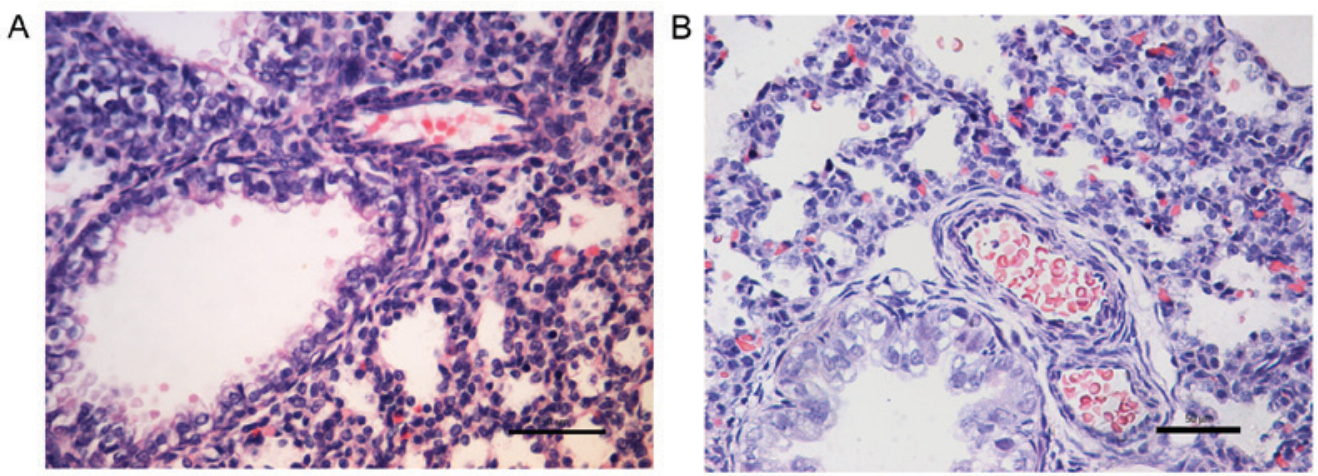

Figure 1. Changes in lung morphology in newborn PPHN model rat lungs. Lung sections were stained with hematoxylin and eosin, and images were captured under a light microscope; magnification, $\mathrm{x} 40$; scale bar, $50 \mu \mathrm{m}$. Representative lung histological sections of the (A) control group and (B) the PPHN group. When compared with the (A) control group, the small pulmonary artery wall was thicker in the (B) PPHN group. PPHN, persistent pulmonary hypertension of the newborn.
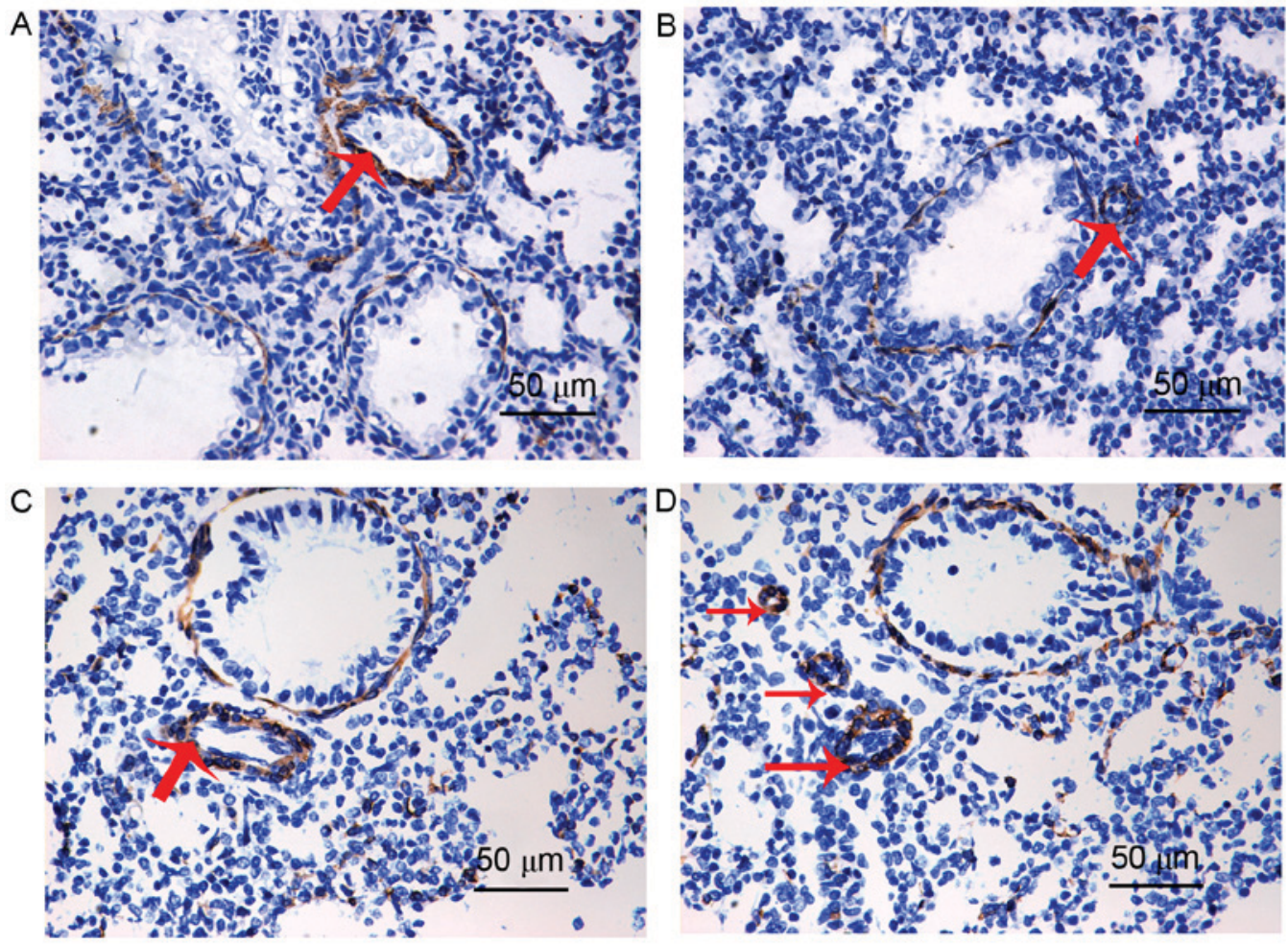

Figure 2. Immunohistochemical staining for $\alpha$-SMA in lung tissue sections isolated from newborn Control and PPHN model rats. Representative lung histological sections of (A and B) control and (C and D) PPHN are shown. An increase in medial thickness in pulmonary arteries in (C) PPHN group compared to (A) control. When compared with the (B) control group, the distal pulmonary arterioles were greatly increased in the (D) PPHN group. Magnification, $\mathrm{x} 40$; scale bar, $50 \mu \mathrm{m}$; red arrows indicate pulmonary arterioles (in A and C) and distal pulmonary arterioles (in B and D). $\alpha$-SMA, $\alpha$ smooth muscle actin; PPHN, persistent pulmonary hypertension of the newborn.

whereas the plasma BNP concentration was $139 \pm 7 \mathrm{pg} / \mathrm{ml}$ in the control group $(\mathrm{P}<0.01$; Fig. 3D).

PPAR- $\gamma$, TRPC1 and TRPC6 protein localization in lung tissues. PPAR- $\gamma$, TRPC1 and TRPC6 protein expression and localization in lung tissues were examined by immunohistochemical staining (Fig. 4). PPAR- $\gamma$ protein expression was observed in the cytoplasm and nuclei of pulmonary vascular endothelial cells and PASMCs. PPAR- $\gamma$ expression in the PPHN group was notably lower compared with the control group. TRPC1 and TRPC6 protein expressions were observed in the cytoplasm of PASMCs, and the expression of both proteins appeared to be greatly increased in the PPHN group compare with rats in the control group.

The results of western blot analysis demonstrated that the protein expression level of PPAR- $\gamma$ was significantly decreased in the PPHN group compared with the control group (Fig. 5; $\mathrm{P}<0.05)$. In the PPHN group, the expression levels of TRPC1 and TRPC6 proteins in lung tissues greatly increased (Fig. 5; $\mathrm{P}<0.05)$.

mRNA expression levels of PPAR- $\gamma$, TRPC1 and TRPC6 in lung tissues. The mRNA expression level of PPAR- $\gamma$ in the PPHN group was significantly lower than the levels detected 


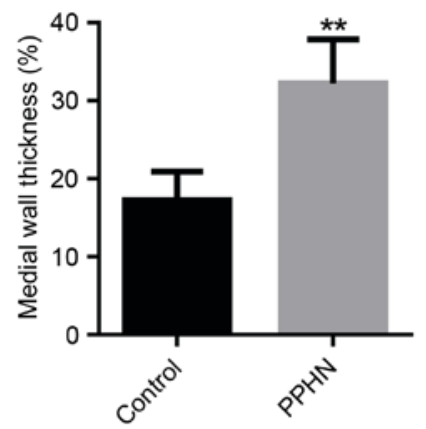

C

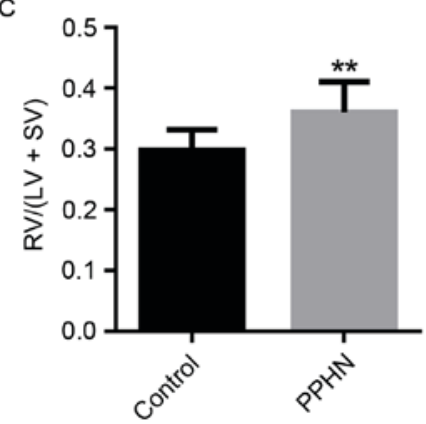

B

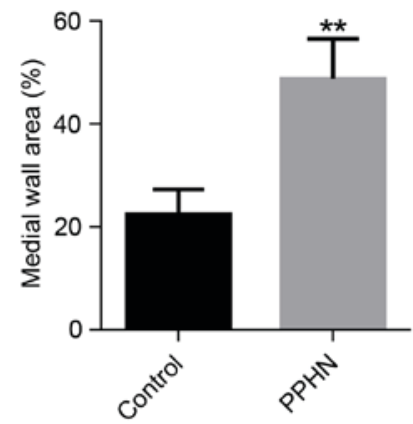

D

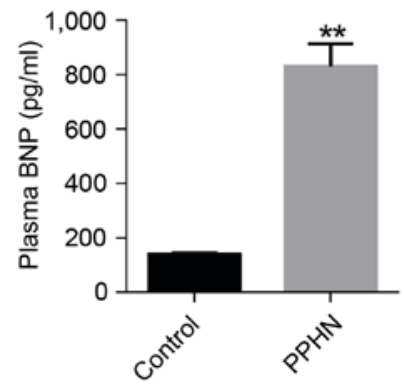

Figure 3. Evaluation of the PPHN model using different parameters. (A) Medial wall thickness percentage (WT \%) of pulmonary arteries between 50 and $100 \mu \mathrm{m}$ in diameter. Medial wall thickness $(\%)=(2 \mathrm{x}$ medial wall thickness)/external diameter. (B) Medial wall area percentage (WA \%) from pulmonary arteries between 50 and $100 \mu \mathrm{m}$ in diameter. Medial wall area $(\%)=$ medial wall area/total area. (C) The ratio of RV/(LV + SV). (D) Plasma BNP concentration. Data are represented as the mean \pm standard deviation; $\mathrm{n}=10$ /group; ${ }^{* * *} \mathrm{P}<0.01$ vs. Control. BNP, B-type natriuretic peptide; LV, left ventricle; PPHN, persistent pulmonary hypertension of the newborn; RV, right ventricle; SV, ventricular septum.

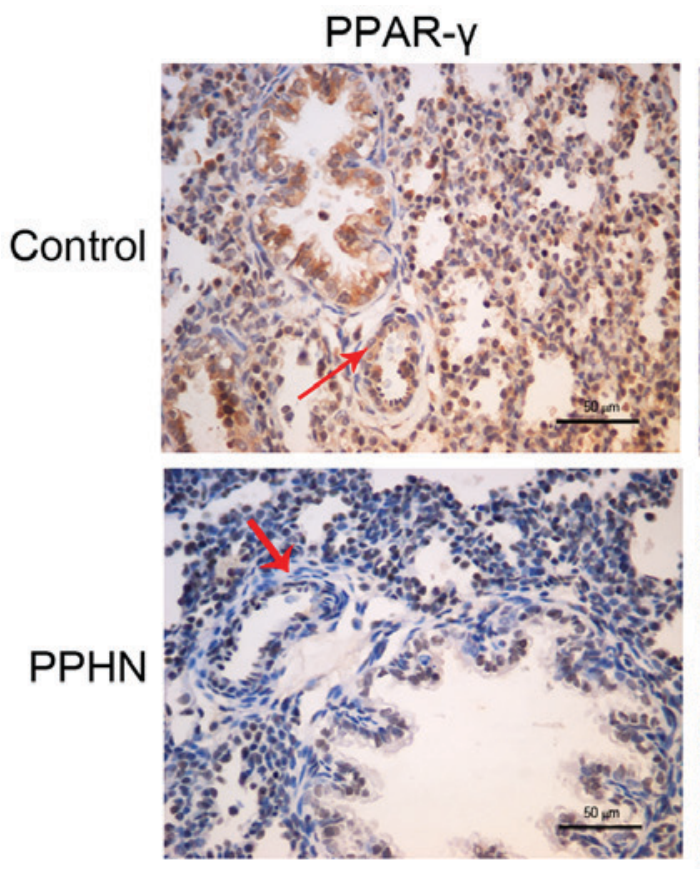

\section{TRPC1}
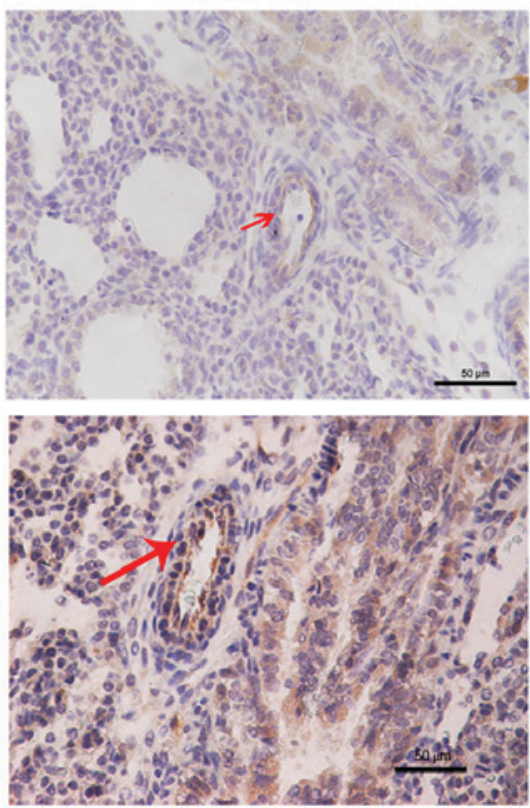

TRPC6
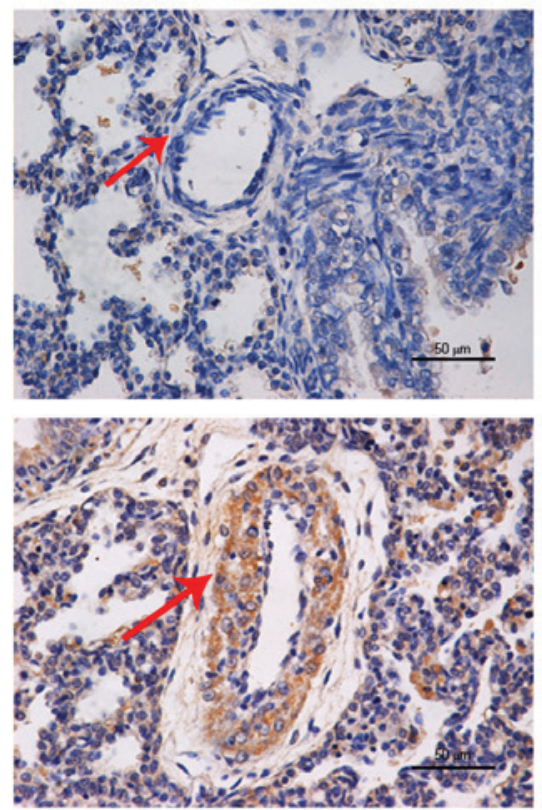

Figure 4. Immunohistochemical staining for PPAR- $\gamma$, TRPC1 and TRPC6 protein expression in lung tissues isolated from newborn control and PPHN model rats. PPAR- $\gamma$ is expressed in the nucleus and cytoplasm of pulmonary vascular endothelial cells and smooth muscle cells relative immunostaining density for PPAR- $\gamma$ in pulmonary arterioles in the PPHN group was notably lower compared with the control group. TRPC1 and TRPC6 proteins were expressed in the cytoplasm of the pulmonary smooth muscle cells and pulmonary epithelial cells. Compared with the control group, TRPC1 and TRPC6 protein expressions were greatly increased in the pulmonary arterioles of the PPHN group. Scale bar, $50 \mu \mathrm{m}$; red arrows indicate pulmonary arterioles. PPAR- $\gamma$, peroxisome proliferator-activated receptor $\gamma$; PPHN, persistent pulmonary hypertension of the newborn; TRPC, transient receptor potential cation channel.

in the control group (Fig. 6A; $\mathrm{P}<0.01$ ). However, no significant differences were identified in the mRNA expression levels of
TRPC1 and TRPC6 in the PPHN group compared with the control group (Fig. 6B and $\mathrm{C} ; \mathrm{P}>0.05$ ). 


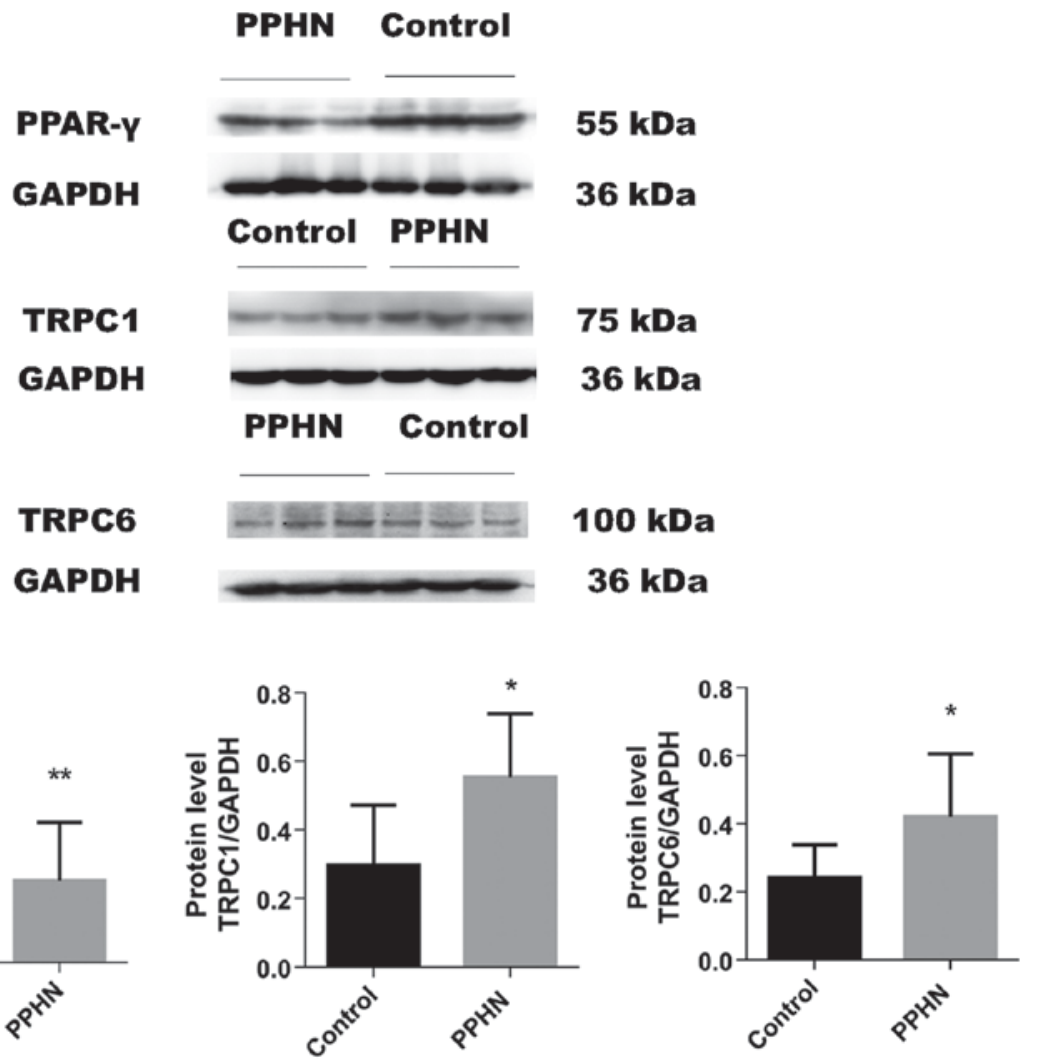

Figure 5. PPAR- $\gamma$, TRPC1 and TRPC6 protein expression analysis. The protein expression levels of PPAR- $\gamma$, TRPC1 and TRPC6 were measured by western blotting, and the intensity of the bands was normalized to GAPDH. Data were presented as the mean \pm standard deviation; $\mathrm{n}=8 /$ group; ${ }^{*} \mathrm{P}<0.05$ and ${ }^{* *} \mathrm{P}<0.01 \mathrm{vs}$. Control. PPAR- $\gamma$, peroxisome proliferator-activated receptor $\gamma$; PPHN, persistent pulmonary hypertension of the newborn; TRPC, transient receptor potential cation channel.

A

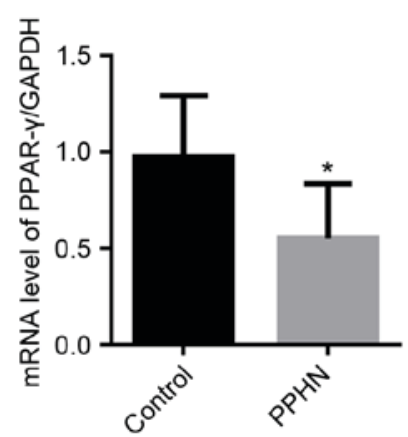

B

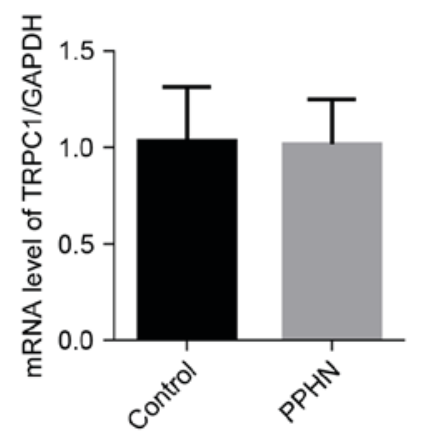

C

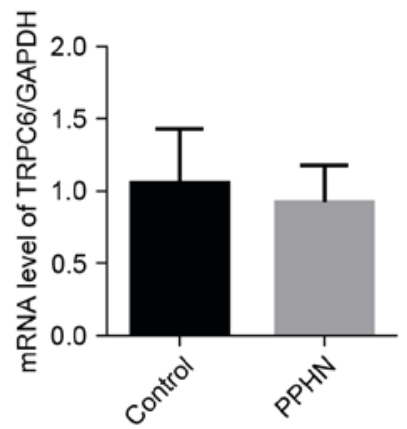

Figure 6. mRNA expression levels of PPAR- $\gamma$, TRPC1 and TRPC6. (A) PPAR- $\gamma$, (B) TRPC1 and (C) TRPC6 mRNA expression relative to GAPDH were measured by reverse transcription-quantitative polymerase chain reaction. Data are presented as the mean \pm standard deviation; $\mathrm{n}=8 / \mathrm{group} ;{ }^{*} \mathrm{P}<0.05$ vs Control. PPAR- $\gamma$, peroxisome proliferator-activated receptor $\gamma$; PPHN, persistent pulmonary hypertension of the newborn; TRPC, transient receptor potential cation channel.

\section{Discussion}

PPHN is a severe cardiopulmonary disorder that is characterized by pulmonary vasoconstriction and late pulmonary vascular remodeling, which results in significantly increased pulmonary arterial pressure and right ventricular hypertrophy $(23,24)$. PPHN mainly affects full-term infants and near full-term infants, but may also affect premature infants (25), and the prevalence of PPHN is 0.43-6.8 per 1,000 births, with a mortality rate of $10-20 \%$ (19). Furthermore, PPHN has long-term complications, including neurodevelopmental, cognitive and hearing abnormalities (26). Therefore, there is a necessity and urgency to elucidate the underlying mechanism for the pathogenesis of PPHN.

Indomethacin is widely used to treat patent ductus arteriosus in human neonates $(27,28)$. Previous studies have demonstrated that a partial ligation of the arterial duct in utero was able to induce PPHN in sheep $(29,30)$. PH has also been reported to be induced by continuous hypoxia (31-33). In addition, a previous report demonstrated that the combination of indomethacin and hypoxia was able to successfully established PPHN in rats (21). The present study used a similar concept, 
which combined exposure to hypoxic conditions with indomethacin treatment to establish a PPHN rat model in prenatal rats during days 19-21 of gestation. The results demonstrated that WA \% and WT \% were markedly increased in the PPHN group compared with rats in the control group. These results suggested that the PASMCs were significantly increased and that pulmonary vascular remodeling was present in the PPHN group. In addition, the expression of $\alpha$-SMA in fibroblasts was greatly increased in the PPHN group compared with the control group. This increase in $\alpha$-SMA content may indicate that, when compared with the control group, distal muscularization of the pulmonary arteries was increased in the PPHN group.

BNP is used to determine the severity of right ventricular failure and outcomes from PH in humans (34). In the present study, plasma BNP concentrations were significantly higher in rats in the PPHN group compared with the control group, suggesting that the PPHN group may have an enhanced degree of PH. To further examine the state of $\mathrm{PH}$ in the PPHN group $\mathrm{RV} /(\mathrm{LV}+\mathrm{SV})$ was calculated, which is used to evaluate right ventricle hypertrophy. Overall, the PPHN group exhibited a significant increase in pulmonary artery pressure and in the thickness of pulmonary artery medial smooth muscle, as well as right ventricular hypertrophy. These results indicated that the PPHN rat model was successfully established.

A number of previous studies have demonstrated that the loss of PPAR- $\gamma$ expression may be closely related to PH. One study reported that mice with a targeted deletion of PPAR- $\gamma$ in PASMCs developed PH in addition to increased muscularization of the distal pulmonary arteries (16). In addition, the PPAR- $\gamma$ agonist rosiglitazone was revealed to ameliorate $\mathrm{PH}$ in rat and mouse models. For example, rosiglitazone was reported to attenuate the development of $\mathrm{PH}$ and pulmonary vascular remodeling in hypoxia-induced PH model rats (35). Another study demonstrated that treatment with PPAR- $\gamma$ agonists was able to attenuate hypoxia-induced pulmonary vascular remodeling and $\mathrm{PH}$ by suppressing oxidative and proliferative signals in mice (36). Furthermore, treatment of PH with pioglitazone, another PPAR- $\gamma$ agonist, was reported to decrease pulmonary arterial systolic pressure, medial wall thickness and muscularization of small pulmonary arteries (15). The present study revealed that the expression of PPAR- $\gamma$ in newborn rat lung tissues was decreased in the PPHN group, leading to the hypothesis that PPAR- $\gamma$ may serve a protective role in the pathophysiology of PPHN.

Over the past several years, a number of studies have demonstrated that increased concentration of intracellular $\mathrm{Ca}^{2+}$ is a major stimulus for PASMC proliferation and migration (11). A previous study has also indicated that the hypoxia-enhanced SOCE through the SOCC is highly associated with the elevated concentration of $\mathrm{Ca}^{2+}(11)$. In PASMCs of hypoxia-induced $\mathrm{PH}$ and monocrotaline-induced $\mathrm{PH}$ (37), the canonical TRPCs are important aspects of the SOCC, in which TRPC1, TRPC4 and TRPC6 are significantly expressed in the rat pulmonary artery and PASMCs (38). Chronic hypoxia was reported to increase the expression of TRPC1 and TRPC6 (38), but not TRPC4 expression, in PASMCs isolated from rats as well as in cultured PASMCs (39). Based on these reports, the present study hypothesized that TRPC1 and TRPC6 were related to the pathophysiology of PPHN.
To test this hypothesis, the expression levels of TRPC1 and TRPC6 were examined in PPHN model rats. Although no differences were observed in the mRNA expression levels of TRPC1 and TRPC6, the protein expression levels of TRPC1 and TRPC6 were significantly increased in the lung tissues isolated from the PPHN group. The inconsistency of mRNA and protein expression in TRPC1 and TRPC6 may be due to posttranscriptional modifications (40). These results indicated that upregulated expression levels of TRPC1 and TRPC6 protein may account for the pathogenesis of PPHN.

A recent report demonstrated that PPAR- $\gamma$ may inhibit chronic hypoxia-induced $\mathrm{PH}$ by downregulating the expression of TRPC1 and TRPC6 (10). In addition, sildenafil was reported to attenuate $\mathrm{PH}$ as indicated by a reduction in the levels of SOCE and downregulation of TRPC1 and TRPC6 expression in rat PASMCs via the cyclic GMP/protein kinase G/PPAR- $\gamma$ axis (41). Another study reported that PPAR- $\gamma$ inhibited hypoxia-induced SOCE by downregulating caveolin-1 expression or downregulating TRPC1 and TRPC6 expression (11), which suggested that PPAR- $\gamma$ may inhibit PPHN by downregulating the expression of TRPC1 and TRPC6 or caveolin-1.

In conclusion, the present study established a PPHN rat model and observed altered expressions of PPAR- $\gamma$, TRPC1 and TRPC6 in the pulmonary artery located in the lungs of newborn rats with PPHN, suggesting that these proteins may be important mediators of PPHN. It was also speculated that PPAR- $\gamma$ may inhibit PPHN by upregulating the expression of TRPC1 and TRPC6. Further investigations are required to verify these results and to elucidate the underlying mechanisms for the pathogenesis of PPHN.

\section{Acknowledgements}

The present study was supported by The National Natural Science Foundation of China (grant nos. 81471489 and 81571479).

\section{References}

1. Jain A and McNamara PJ: Persistent pulmonary hypertension of the newborn: Advances in diagnosis and treatment. Semin Fetal Neonatal Med 20: 262-271, 2015.

2. Keith IM, Tjen-A-Looi S, Kraiczi H and Ekman R: Three-week neonatal hypoxia reduces blood CGRP and causes persistent pulmonary hypertension in rats. Am J Physiol Heart Circ Physiol 279: H1571-H1578, 2000.

3. Afolayan AJ, Eis A, Alexander M, Michalkiewicz T, Teng RJ, Lakshminrusimha S and Konduri GG: Decreased endothelial nitric oxide synthase expression and function contribute to impaired mitochondrial biogenesis and oxidative stress in fetal lambs with persistent pulmonary hypertension. Am J Physiol Lung Cell Mol Physiol 310: L40-L49, 2016.

4. Steinhorn RH: Neonatal pulmonary hypertension. Pediatr Crit Care Med 11 (2 Suppl): 79-84, 2010.

5. Postolow F, Fediuk J, Nolette N, Hinton M and Dakshinamurti S: Thromboxane promotes smooth muscle phenotype commitment but not remodeling of hypoxic neonatal pulmonary artery. Fibrogenesis Tissue Repair 8: 20, 2015.

6. Sluiter I, Reiss I, Kraemer U, Krijger Rd, Tibboel D and Rottier RJ: Vascular abnormalities in human newborns with pulmonary hypertension. Expert Rev Respir Med 5: 245-256, 2011.

7. Guo SJ, Wang T, Jia LQ, Li DD, Shen YC, Xu D and Wen FQ: TRAM-34 attenuates hypoxia induced pulmonary artery smooth muscle cell proliferation. Eur Rev Med Pharmacol Sci 19: 3515-3521, 2015. 
8. Wan J, Yamamura A, Zimnicka AM, Voiriot G, Smith KA, Tang H, Ayon RJ, Choudhury MS, Ko EA, Wang J, et al: Chronic hypoxia selectively enhances L- and T-type voltage-dependent $\mathrm{Ca}^{2+}$ channel activity in pulmonary artery by upregulating Cav1.2 and Cav3.2. Am J Physiol Lung Cell Mol Physiol 305: L154-L164, 2013.

9. Yamamura A, Yamamura H, Zeifman A and Yuan JX: Activity of $\mathrm{Ca}$-activated $\mathrm{Cl}$ channels contributes to regulating receptorand store-operated $\mathrm{Ca}$ entry in human pulmonary artery smooth muscle cells. Pulm Circ 1: 269-279, 2011.

10. Wang Y, Lu W, Yang K, Wang Y, Zhang J, Jia J, Yun X, Tian L, Chen Y, Jiang Q, et al: Peroxisome proliferator-activated receptor gamma inhibits pulmonary hypertension targeting store-operated calcium entry. J Mol Med (Berl) 93: 327-342, 2015.

11. Yang K, Lu W, Jiang Q, Yun X, Zhao M, Jiang H and Wang J: Peroxisome proliferator-activated receptor $\gamma$-mediated inhibition on hypoxia-triggered store-operated calcium entry. A caveolin-1-dependent mechanism. Am J Respir Cell Mol Biol 53: 882-892, 2015.

12. Nawar NN, Mohamed AH, Adieb N and Emad M: The effect of maternal Naja nigricollis envenomation on the placenta. An experimental study. Biol Struct Morphog 2: 13-17, 1989.

13. Zhang D, Wang G, Han D, Zhang Y, Xu J, Lu J, Li S, Xie X, Liu L, Dong L and Li M: Activation of PPAR- $\gamma$ ameliorates pulmonary arterial hypertension via inducing heme oxygenase-1 and p21(WAF1): An in vivo study in rats. Life Sci 98: 39-43, 2014.

14. Takano $\mathrm{H}$ and Komuro I: Peroxisome proliferator-activated receptor gamma and cardiovascular diseases. Circ J 73: 214-220, 2009.

15. Behringer A, Trappiel M, Berghausen EM, Ten Freyhaus H, Wellnhofer E, Odenthal M, Blaschke F, Er F, Gassanov N, Rosenkranz S, et al: Pioglitazone alleviates cardiac and vascular remodelling and improves survival in monocrotaline induced pulmonary arterial hypertension. Naunyn Schmiedebergs Arch Pharmacol 389: 369-379, 2016.

16. Hansmann G, de Jesus Perez VA, Alastalo TP, Alvira CM, Guignabert C, Bekker JM, Schellong S, Urashima T, Wang L, Morrell NW and Rabinovitch M: An antiproliferative BMP-2/PPARgamma/apoE axis in human and murine SMCs and its role in pulmonary hypertension. J Clin Invest 118: 1846-1857, 2008.

17. Bijli KM, Kleinhenz JM, Murphy TC, Kang BY, Adesina SE, Sutliff RL and Hart CM: Peroxisome proliferator-activated receptor gamma depletion stimulates Nox4 expression and human pulmonary artery smooth muscle cell proliferation. Free Radic Biol Med 80: 111-120, 2015.

18. Xie X, Wang G, Zhang D, Zhang Y, Zhu Y, Li F, Li S and Li M: Activation of peroxisome proliferator-activated receptor $\gamma$ ameliorates monocrotaline-induced pulmonary arterial hypertension in rats. Biomed Rep 3: 537-542, 2015.

19. Xu XF, Ma XL, Shen Z, Wu XL, Cheng F and Du LZ: Epigenetic regulation of the endothelial nitric oxide synthase gene in persistent pulmonary hypertension of the newborn rat. J Hypertens 28 : 2227-2235, 2010.

20. Fabris VE, Pato MD and Belik J: Progressive lung and cardiac changes associated with pulmonary hypertension in the fetal rat. Pediatr Pulmonol 31: 344-353, 2001

21. Xu XF, Gu WZ, Wu XL, Li RY and Du LZ: Fetal pulmonary vascular remodeling in a rat model induced by hypoxia and indomethacin. J Matern Fetal Neonatal Med 24: 172-182, 2011.

22. Livak KJ and Schmittgen TD: Analysis of relative gene expression data using real-time quantitative PCR and the 2(-Delta Delta C(T)) Method. Methods 25: 402-408, 2001.

23. Stayer SA and Liu Y: Pulmonary hypertension of the newborn. Best Pract Res Clin Anaesthesiol 24: 375-386, 2010.

24. Dakshinamurti S: Pathophysiologic mechanisms of persistent pulmonary hypertension of the newborn. Pediatr Pulmonol 39 492-503, 2005.
25. Cabral JE and Belik J: Persistent pulmonary hypertension of the newborn: Recent advances in pathophysiology and treatment. J Pediatr (Rio J) 89: 226-242, 2013.

26. Nair J and Lakshminrusimha S: Update on PPHN: Mechanisms and treatment. Semin Perinatol 38: 78-91, 2014

27. Lemmers PM,Benders MJ,D'Ascenzo R,Zethof J, Alderliesten T, Kersbergen KJ, Isgum I, de Vries LS, Groenendaal F and van BelF: Patent ductus arteriosus and brain volume. Pediatrics 137: pii: e20153090, 2016

28. Louis D, Torgalkar R, Shah J, Shah PS and Jain A: Enteral feeding during indomethacin treatment for patent ductus arteriosus: Association with gastrointestinal outcomes. J Perinatol 36: 544-548, 2016.

29. Dodson RB, Morgan MR, Galambos C, Hunter KS and Abman SH: Chronic intrauterine pulmonary hypertension increases main pulmonary artery stiffness and adventitial remodeling in fetal sheep. Am J Physiol Lung Cell Mol Physiol 307: L822-L828, 2014.

30. Konduri GG, Bakhutashvili I, Eis A and Afolayan A: Antenatal betamethasone improves postnatal transition in late preterm lambs with persistent pulmonary hypertension of the newborn. Pediatr Res 73: 621-629, 2013.

31. Yang K, Lu W, Jia J, Zhang J, Zhao M, Wang S, Jiang H, Xu L and Wang J: Noggin inhibits hypoxia-induced proliferation by targeting store-operated calcium entry and transient receptor potential cation channels. Am J Physiol Cell Physiol 308: C869-C878, 2015.

32. Sun H, Xia Y, Paudel O, Yang XR and Sham JS: Chronic hypoxia-induced upregulation of $\mathrm{Ca}^{2+}$-activated $\mathrm{Cl}^{-}$channel in pulmonary arterial myocytes: A mechanism contributing to enhanced vasoreactivity. J Physiol 590: 3507-3521, 2012.

33. Peng G, Wang J, Lu W and Ran P: Isolation and primary culture of rat distal pulmonary venous smooth muscle cells. Hypertens Res 33: 308-313, 2010

34. Jone PN, Patel SS, Cassidy C and Ivy DD: Three-dimensional echocardiography of right ventricular function correlates with severity of pediatric pulmonary hypertension. Congenit Heart Dis 11: $562-569,2016$

35. Kim EK, Lee JH, Oh YM, Lee YS and Lee SD: Rosiglitazone attenuates hypoxia-induced pulmonary arterial hypertension in rats. Respirology 15: 659-668, 2010.

36. Nisbet RE, Bland JM, Kleinhenz DJ, Mitchell PO, Walp ER, Sutliff RL and Hart CM: Rosiglitazone attenuates chronic hypoxia-induced pulmonary hypertension in a mouse model. Am J Respir Cell Mol Biol 42: 482-490, 2010.

37. Guo Q, Huang JA, Yamamura A, Yamamura H, Zimnicka AM, Fernandez R and Yuan JX: Inhibition of the $\mathrm{Ca}(2+)$-sensing receptor rescues pulmonary hypertension in rats and mice. Hypertens Res 37: 116-124, 2014.

38. Yun X, Chen Y, Yang K, Wang S, Lu W and Wang J: Upregulation of canonical transient receptor potential channel in the pulmonary arterial smooth muscle of a chronic thromboembolic pulmonary hypertension rat model. Hypertens Res 38: 821-828, 2015.

39. Wang J, Weigand L, Lu W, Sylvester JT, Semenza GL and Shimoda LA: Hypoxia inducible factor 1 mediates hypoxia-induced TRPC expression and elevated intracellular $\mathrm{Ca}^{2+}$ in pulmonary arterial smooth muscle cells. Circ Res 98: 1528-1537, 2006.

40. Lotfi K, Karlsson K, Fyrberg A, Juliusson G, Jonsson V, Peterson C, Eriksson S and Albertioni F: The pattern of deoxycytidine- and deoxyguanosine kinase activity in relation to messenger RNA expression in blood cells from untreated patients with B-cell chronic lymphocytic leukemia. Biochem Pharmacol 71: 882-890, 2006.

41. Wang J, Yang K, Xu L, Zhang Y, Lai N, Jiang H, Zhang Y, Zhong N, Ran P and Lu W: Sildenafil inhibits hypoxia-induced transient receptor potential canonical protein expression in pulmonary arterial smooth muscle via cGMP-PKG-PPAR $\gamma$ axis. Am J Respir Cell Mol Biol 49: 231-240, 2013. 